\title{
Applications of bioinspired approaches and challenges in medical devices
}

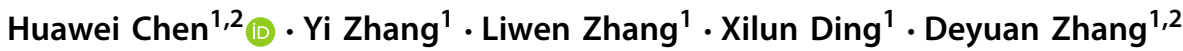

Received: 5 October 2020 / Accepted: 6 October 2020 / Published online: 7 November 2020

(c) The Author(s) 2020

\section{Urgent requirements of medical devices}

Precision medicine has gradually become a development strategy in many countries and attracted worldwide attention in recent years due to the increasing concerns in public health. Although the definition of precision medicine has less or more difference from the viewpoints of different fields, the demands on the properties of medical devices or medical materials involving biocompatibility and anti-thrombosis are gradually growing much more diverse and much more urgent than ever [1]. This trend brings up many new research topics about materials, mechanical systems and sensors to develop advanced medical devices. How to design and on-demand fabricate the bio-materials, bio-interface and bio-systems to meet the urgent demands of medical devices is still a challenge for us.

\section{Importance of bionics in medical device}

The medical device generally refers to the implantable [2], interventional medical device, surgical devices and so on, which interact with soft tissue directly or indirectly. All the demands on the medical device should consider the requirements of life system, which consists of
- Good physiological compatibility

- Desirable surface function such as anti-fogging or antiadhesion

- Sufficient strength for biomaterial

- Low soft tissue damage for surgery, etc.

Medical treatment is to recover the function of life system or to recuperate the health from illness. To improve the healing quality, it is very necessary to make clear the physiological and functional mechanisms of tissue and organs. Accordingly, the knowledge of these physiological mechanisms, hierarchical structures' function and behavior of whole living beings can give us inspirations to enhance the medical devices, which is also the base of bionics. Bioinspired approaches have been applied in the medical devices recently, such as bioinspired materials, bioinspired functional surfaces and bioinspired sensors [3-5]. Here, we just focus attention on applications of bioinspired surface to explore the importance of bionics in medical devices (Fig. 1).
Huawei Chen

chenhw75@buaa.edu.cn

1 School of Mechanical Engineering and Automation, Beihang University, Beijing, China

2 Beijing Advanced Innovation Center for Biomedical Engineering, Beihang University, Beijing, China 


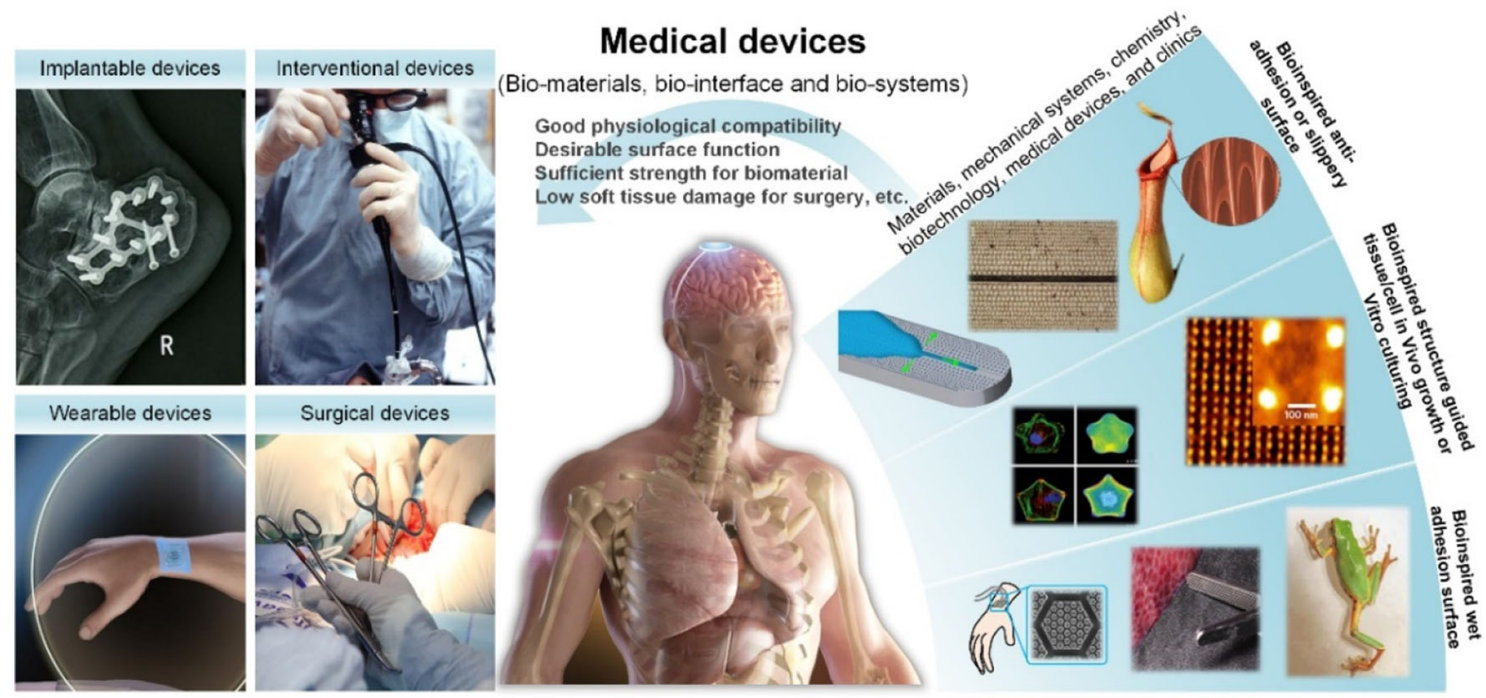

Fig. 1 Schematic of bio-inspired approaches for medical devices

\section{Advances of biomimetic surfaces in medical devices}

\section{How to choose the natural surface for bionics}

Diverse surface functions have been found in various natural species, which is indispensable to medical devices such as anti-fouling, anti-adhesion and strong wet attachment. As the principle for bionic object selection, the similarity of application conditions and surface function's demand should be considered. Because the contact interface of medical devices against soft tissue is generally wet, it is better to choose a natural surface possessing superior function in wet conditions. For example, a new idea of anti-slipping surface can be got from tree frog; the anti-adhesion mechanism of Nepenthes alata's peristome and lotus leaves can help us developing anti-adhesion or anti-fouling surface.

\section{Bioinspired anti-adhesion or slippery surface}

Adhesion of soft tissue on the medical devices commonly arises. Thrombosis forms as fibrin and platelets adhere to the surface of the vascular stents in the blood; the soft tissue adheres to the surface of electrical scalpel in the minimally invasive surgery (MIS). A slippery liquid-infused surface, which is inspired by the Nepenthes pitcher plant, was built instead of commonly used superhydrophobic coating [6]. Such slippery surface can prevent the adhesion to the substrate by a formation of stable liquid layer as like the Nepenthes pitcher plant prevents the attachments of insects by using a thin layer of liquid to create a low friction surface, which has been widely used in electrical scalpel and lens of endoscope.

\section{Bioinspired wet attachment surface}

As well, strong wet attachment even without any external load as like tree frog is another desired surface function to achieve low damage of soft tissue [7]. Unique liquid adjusting behaviors were found on the toe pad of tree frog to form strong liquid bridge by self-splitting and self-sucking effect. Under the inspiration of tree frog and octopus, bioinspired hierarchical structure with superior wet attachment has been applied in heart patch, medical electrode and tissue grasper of MIS. Not only strong wet attachment but also reduction of the soft tissue damage can be achieved.

\section{Bioinspired structure guided tissue/cell in vivo growth or vitro culturing}

Tissue/cell in vivo growth and in vitro culturing are remarkably important for implantable medical devices and drug evaluation [8]. In order to achieve desired growth and reproduction, it is necessary to construct the culturing conditions and the growing structure as close to living being as possible. Bioinspired surface was applied to the dental implants to improve the implanting quality. Bioinspired gradient porous structure was built on the bone scaffolds to guide and improve the tissue growth. Especially, for in vitro culturing devices, the culturing environment should be ensured by mimicking the actual living condition of soft tissue and cell.

\section{Challenges and perspective}

Bioinspired hierarchical surface structures are demonstrated by tracking the biomimetic methods applied in the medi- 
cal devices. Through the applications in MIS, bioinspired approaches have provided promising solutions for solving the adhesion and slippery problems commonly appearing in MIS medical devices. However, the applications of bioinspired approaches in the medical devices are still far from our expectations due to lack of sound design theory and costeffective fabrication approaches for bioinspired functional structure, surface and even systems. The barrier encountered with bioinspired approaches for the current medical devices is how to create artificial, biocompatible interfaces that can guide or coordinate with the functions of biological cells, mimicking the physical and chemical properties of biological surfaces. Thus, the following challenges and issues should be overcome.

- Comprehensive cognition of biological function mechanism or behaviors

- Interaction mechanism between artificial hierarchical structure and biological cells, soft tissue, etc., in biology

- Multi-function-oriented biocompatible structure or interface design principle

- Cost-effective fabrication approaches for biocompatible multiscale, multi-material structures

- In vivo life-cycle assessment

Bioinspired approaches can be widely used in biomaterial, bio-interface, biosensor or even bio-printing process [9]. As an interdisciplinary research, it is without doubt that any development needs comprehensive cooperation from materials, chemistry, biotechnology, medical devices and clinics. We hope this perspective will attract the attention of worldwide scholars in related areas to develop bioinspired medical devices for the welfare of mankind.

Author contributions HW, LW and ZY contributed to writing and editing; XL and DY helped in writing, and editing and validation; HW, LW and ZY contributed to formal analysis and data curation; HW contributed to resources, project administration, and funding acquisition.

\section{Compliance with ethical standards}

Conflict of interest The authors declare that there is no conflict of interest.
Ethical approval This study does not contain any studies with human or animal subjects performed by any of the authors.

Open Access This article is licensed under a Creative Commons Attribution 4.0 International License, which permits use, sharing, adaptation, distribution and reproduction in any medium or format, as long as you give appropriate credit to the original author(s) and the source, provide a link to the Creative Commons licence, and indicate if changes were made. The images or other third party material in this article are included in the article's Creative Commons licence, unless indicated otherwise in a credit line to the material. If material is not included in the article's Creative Commons licence and your intended use is not permitted by statutory regulation or exceeds the permitted use, you will need to obtain permission directly from the copyright holder. To view a copy of this licence, visit http://creativecomm ons.org/licenses/by/4.0/.

\section{References}

1. Saroia J, Yanen W, Wei Q, Zhang K, Lu T, Zhang B (2018) A review on biocompatibility nature of hydrogels with 3D printing techniques, tissue engineering application and its future prospective. Bio-Design Manuf 1(4):265-279

2. Dong XP, Zhang YW, Pei YJ, Wang Z, Zhang XX, Yu XL, Mei YX, Li JN (2020) Three-dimensional printing for the accurate orthopedics: clinical cases analysis. Bio-Design Manuf 3:122-132

3. Wegst UGK, Bai H, Saiz E, Tomsia AP, Ritchiel RO (2015) Bioinspired structural materials. Nature Mater 14:23-36

4. Zhang PF, Liu G, Zhang DY, Chen HW (2018) Liquid-infused surfaces on electrosurgical instruments with exceptional antiadhesion and low damage performances. ACS Appl Mater Interfaces 10:33713-33720

5. Jung YH, Park B, Kim JU, Kim T-i (2018) Bioinspired electronics for artificial sensory systems. Adv Mater 31(34):201803637

6. Chen H, Zhang P, Zhang L, Liu H, Jiang Y, Zhang D, Han Z, Jiang $\mathrm{L}$ (2016) Continuous directional water transport on the peristome surface of Nepenthes alata. Nature 532(7597):85-89

7. Zhang L, Chen H, Guo Y, Wang Y, Jiang Y, Zhang D, Ma L, Luo J, Jiang L (2020) Micro-nano hierarchical structure enhanced strong wet friction surface inspired by tree frogs. Advanced Science, p. 2001125

8. Dalby MJ, Gadegaard N, Oreffo RO (2014) Harnessing nanotopography and integrin-matrix interactions to influence stem cell fate. Nat Mater 13(6):558-569

9. Gao Q, Gu H, Zhao P, He Y (2018) Fabrication of electrospun nanofibrous scaffolds with 3D controllable geometric shapes. Mater Des 157:159-169 